\title{
Design Focus Group as a Controlled-Experiment Setting
}

\author{
Natrina Mariane P. Toyong, Shahriman Zainal Abidin, S’harin Mokhtar, Rusmadiah Anwar \\ Faculty of Art \& Design, \\ Universiti Teknologi MARA, 40450 Shah Alam Selangor, Malaysia
}

natrinatoy@uitm.edu.my, shahriman.z.a@uitm.edu.my,sharin2066@uitm.edu.my,rusma935@uitm.edu.my Tel: 016206008

\begin{abstract}
This paper argues the flexibility of focus group in Design research as a controlled-experiment setting to study Designerly Intuition at concept-stage decision making. This paper outlines the focus group design in terms of the types and structure considerations and the moderator factor. Finally, the focus-group result gathers dual-mode input from novice Industrial Designers (1) 'as a group' and the intuitive attributes as (2) 'individual participants'. Therefore, the focus group design for the data collection setting is established through the research layout and space design that accommodates both modes of inquiry.
\end{abstract}

Keywords: Focus Group Study, Design Intuition, Design Research, Controlled Experiment

eISSN: 2398-4287@ 2020. The Authors. Published for AMER ABRA cE-Bsby e-International Publishing House, Ltd., UK. This is an open access article under the CC BYNC-ND license (http://creativecommons.org/licenses/by-nc-nd/4.0/). Peer-review under responsibility of AMER (Association of Malaysian Environment-Behaviour Researchers), ABRA (Association of Behavioural Researchers on Asians) and cE-Bs (Centre for Environment-Behaviour Studies), Faculty of Architecture, Planning \& Surveying, Universiti Teknologi MARA, Malaysia.

DOI: https://doi.org/10.21834/ebpj.v5iSI3.2536

\subsection{Introduction}

This study to uncover Designerly Intuition of novice designers is planned as a two-phased, research collection activities. A total of four sessions were conducted with eight participants per session. At every session, phase one required each participant to complete an individual reflective sketching activity. The result, their concept sketches are brought to the next phase which is the group discussion where the design concepts are discussed, argued, defended and brought to conclusion as a team. The Focus Group method in this case is considered the best foundation for the study because of its flexibility and various application in contemporary Design Research. In the design of the experiment set up, the process of uncovering Designerly Intuition through the analysis of designers' activities is reflected in the research set up, specifically in the space design where the decision-making at concept stage occur. The focus group study is one-third of a larger study which triangulates the data sets with that of previously conducted in-depth interview of eight expert-level designers and eight senior-level designers within the same discussion theme of intuitiveness in design. This paper therefore does not go in-depth on the establishment of the topic of inquiry, instead it will discuss the practical consideration of controlled experiment design in a focus group set up.

\begin{tabular}{ll}
\multicolumn{2}{l}{ Nomenclature } \\
A & Designerly \\
B & Design Research \\
C & Focus Group
\end{tabular}

eISSN: 2398-4287C 2020. The Authors. Published for AMER ABRA cE-Bsby e-International Publishing House, Ltd., UK. This is an open access article under the CC BYNC-ND license (http://creativecommons.org/licenses/by-nc-nd/4.0/). Peer-review under responsibility of AMER (Association of Malaysian Environment-Behaviour Researchers), ABRA (Association of Behavioural Researchers on Asians) and cE-Bs (Centre for Environment-Behaviour Studies), Faculty of Architecture, Planning \& Surveying, Universiti Teknologi MARA, Malaysia.

DOI: https://doi.org/10.21834/ebpj.v5iSI3.2536 


\subsection{Literature Review}

\subsection{Design Research}

The discussion in this paper is organized as an analysis on factors related to focus group research design towards building a case for a controlled-experiment setting as considerations when designing focus group for Design Research. This focus group study is one third of the data of a larger research which applies triangulation of data source through a combination of Focus Group and in-depth Interview method as prescribed by Carter, Bryant-Lukosius, DiCenso, Blythe and Nevile (2014) in ensuring the contextual validity (Baskerville, Kaul \& Storey, 2015) as well as quality and credibility of qualitative research findings (Patton, 1999).

The growing Design Research community studies this in depth, cantering around the process of designing in diverse fields with the general objectives of formulating and validating models and theories on the phenomenon of design in order to develop and improve design practice, including education, and its outcomes based on support founded on these theories and models (Blessing, Chakrabarti \& Wallace, 1995). Doorst and Dijkuis (1995) outlined two paradigms for describing design activities; the rational problem solving paradigm by Simon and the reflection-in-action paradigm by Schön. Between the two paradigms, it was discovered that the latter comes closer to the preferred description of the design activity as they are experienced by a designer. The findings are based on the argument that the 'multi-step process of designing is controlled by the designer's decisions' (Cross, 2006) that are determined by the designer's perception. The design as reflection-in-action paradigm works well in the conceptual stage of design where problem is not yet well defined, as is the case for the focus group study defined in this paper.

\subsection{Focus Group}

The focus group method in collecting data materialized as a reaction to the views by social scientists in the 1930s who expressed their dissatisfaction with the commonly used interviewing technique which places questioners' dominance over passive respondents (Krueger, 2014). The establishment of the Focus Group's basic fundamental practice took decades to build and it was not until Merton and Kendall (1946) coined the term 'Focused Interview' and later develop their study alongside Fiske ten year later which expanded the procedures by studying and improving on the limitations of then current process. Although the basic procedural method remains the same, involving investigation in the form of group discussion, as the method matures, it was known by many name. In the earlier years it was referred to as 'Group Interview', 'Focused Interview', 'Group Depth Interview' and 'Focus Group Interview' whilst today, the research community accepts it simply as 'Focus Group' (Merton \& Kendall, 1956), (Merton, Fiske \& Kendall, 2003), (Stewart \& Shamdasani, 2014).

In considering uses of focus group enquiry, numerous discourses have reviewed on the benefit of linking focus group and interviews (Barbour \& Kitzinger, 1998) (Fusch \& Ness, 2015) and using it with other research method (Krueger, 2014) It is worth noting also that clear differentiation of Design Research focus group must be made to define it from other documented styles of focus group; market research approach, academic research approach, public/non-profit approach, participatory approach, as well as other group methods; the nominal group technique, the Delphi technique, brainstorming and synectics and leaderless discussion group (Stewart \& Shamdasani, 2014) discussion group, Design Decision Groups, group meetings and user workshop. Langford and McDonagh (2003) in outlining the role of focus group inquiry in the field of Human Factors, Ergonomics and Design, describes six purposes of focus group (1) understanding users, task and behaviours, (2) identifying problems and establishing user and task needs, (3) establishing frameworks for further research, (4) evaluating existing or proposed design, (5) generating new design concepts and (6) Influencing and supporting decision making. It also acknowledged that correlating to the subjective nature of Design, it is rare to find one project centred on meeting only one purpose of the focus group.

The structure of a focus group may affect its validity and reliability. To ensure content validity, it is important that saturation point is met. Saturation point of the focus group can begin to emerge once the first three to four session per category has been conducted (Langford \& McDonagh, 2003). The argument on number of participants per category vary from 8 to12 people (Stewart \& Shamdasani, 2014), 5 to 8 people (Krueger, 2014), larger group of 8 to12 and smaller groups of 5 to 6 or 3 people (Barbour, 1998). Further discussion on focus group activity will be addressed along with the consideration of the focus group discussion content in section 2.3. The decision on number of participants and sessions need to be considered with other factors such as the expected group dynamics in relation to the activity within the focus group. In the case of multiple method, Fusch and Ness (2015) discussed that after interviewing five senior level executive leaders individually, one could interview 5 to 8 more senior executive level leader as a group to ensure individual and group perspective are collected. Another discourse which presents comprehensive data analysis framework for focus group, highlights the difference between within group saturation and across group saturation (Onwuegbuzie, Dickinson, Leech\& Zoran, 2009). This needs to be taken into consideration when deciding for number of respondents of the three data source (three groups) for this study.

\subsection{Method}

\subsection{Two-Mode Data Collection of Focus Group in a Controlled Experiment set up}

Taking into consideration the various group dynamic which occur within a focus group session, this study considers the two data collection mode based on the Focus Group design as visualised in the following diagram (see Figure 1). The focus group layout (see Figure 2) is designed to accommodate both modes of data collection within one space. Mode 1 will collect the data of the warm up 
session the individual reflective sketching session where each camera is set up to capture two participants. This is done with consideration of the limited number of video recording device at hand.

However, despite seated next to each other, the participants are separated by dividers on the table to allow them to have their own space, thus eliminating the natural tendency to look over their neighbouring activity. At this point, participants are only required to engage in reflective sketching exercise where thought process through verbal narration is not required and no audio are captured. Fresh sets of sketching materials that are properly labelled according to participants numbered codes are provided at each new session. Their corresponding sketches, along with the video clips of their sketching session will provide data sets for the first part of the controlled experiment set-up (see set up in Figure 3).

\section{MODE 1}

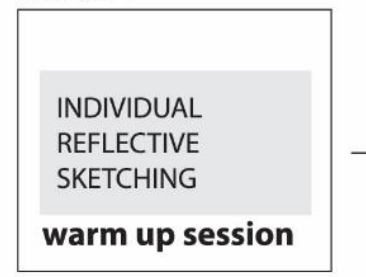

MODE 2

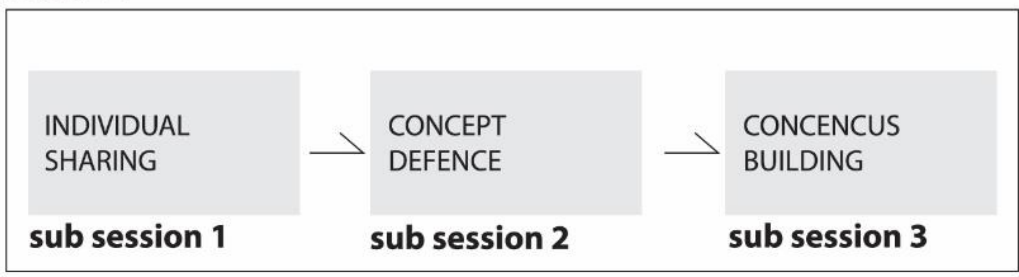

Figure 1: Two-Mode Data Collection of Focus Group as a Controlled Experiment

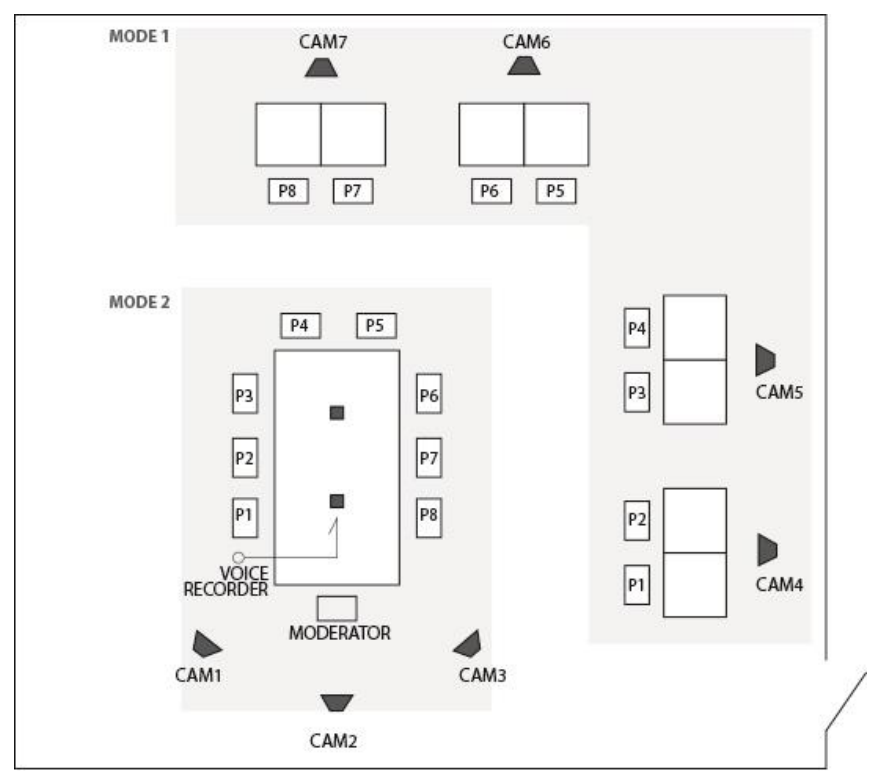

Figure.2: Overall space set-up

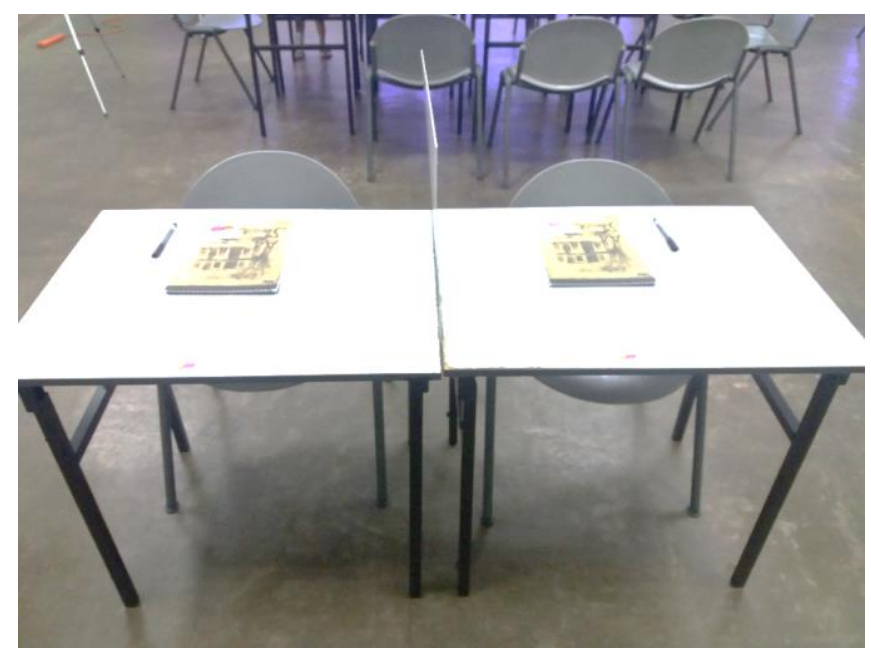

Figure 3: Individual sketching corner with video set-up 
The second data collection requires the verbalization of ideas during the discussion at sub-session 1: Individual Sharing, where the understanding and realization of participants' ideas are built through argument and discussion with the other members at subsession 2: Concept Defence. The discussion is designed to be moderated as a three-part discussion. The first two parts require individual to briefly describe the central idea and concept behind their sketches, upon which other participants can intervene to prompt for further clarification of unclear ideas. Once all participants have had their turn in individually presenting their concept through verbal description of their sketches, the group will be prompted to reach towards a consensus on the best possible concept based on the provided theme.

All the data collection for sub-sessions 1 to 3 happens at Mode 2 where each participants' individual concept sketch will be shared and discussed towards building a group consensus in a rectangular table set up with the moderator at one end. There is a purposeful gap between the distance of the participants with the moderator in this set-up to allow the discussions to happen amongst the participants as opposed to participants talking or presenting to the moderator (see Figure 4). At this point, audio and visual recording are captured using a three-audio-visual camera set up backed up by two audio recorders on the table. Due to the dynamic nature of a focus group discussion, it is important to collect as many back-up data in various format to be able to identify the participants speaking as well as the sequence of argumentations within the discussions later.

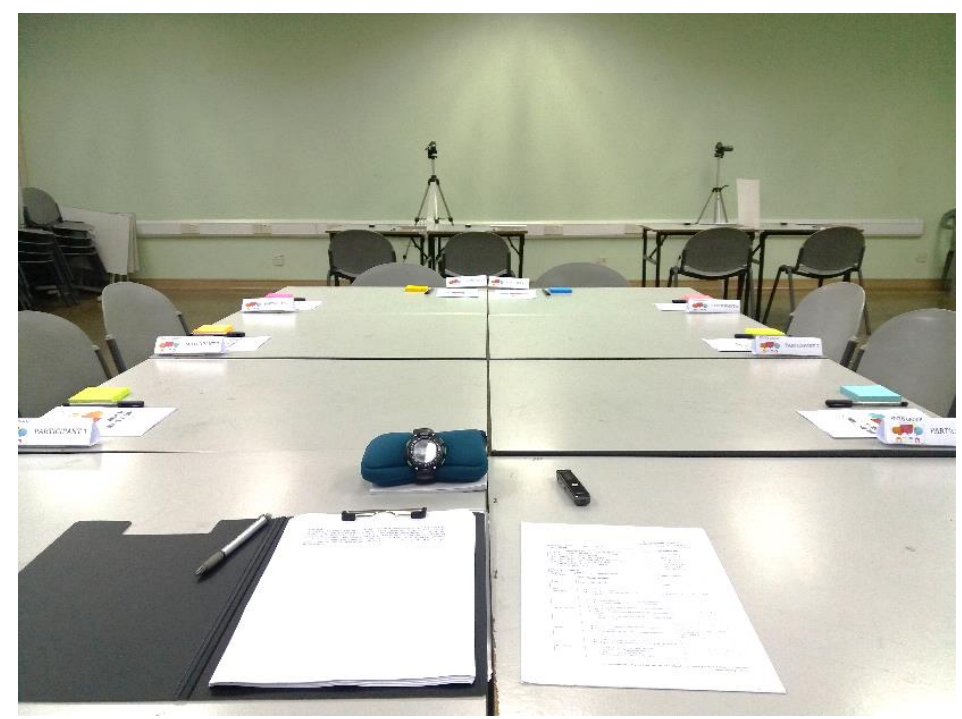

Figure 4: Focus Group Discussion set-up

\subsection{The Focus Group Conduct}

The efficiency of conducting four focus group sessions back-to-back was also considered here with regards to space set up. Each session was conducted by the principal researcher who also serve as moderator for the sessions, aided by a research assistant whose main task requires registering participants and collecting all template documents from the previous session while supplying fresh documents for the next ones. The research conducted has successfully run all four sessions from 8.00am to 6.00pm with 30 minutes time interval for set up for each session and an hour lunch break at noon. As planned, the data collected, in the form of soft copy and hard copy was systematically catalogued after each session, ready to be transcribed and analysed. Another factor in the space set up for this experimental procedure, is the well spaced-out arrangement which allowed for natural movement by participants with minimal navigations or instruction required (see example Figure 5). Since the four-session Focus Group was set in a single day, a natural walk flow set up is important to enable minimal disruption due to confusion. This is important for efficiency, at the same time providing participants a sense of order and control, hence able to focus better on task at hand instead of external environmental factors.
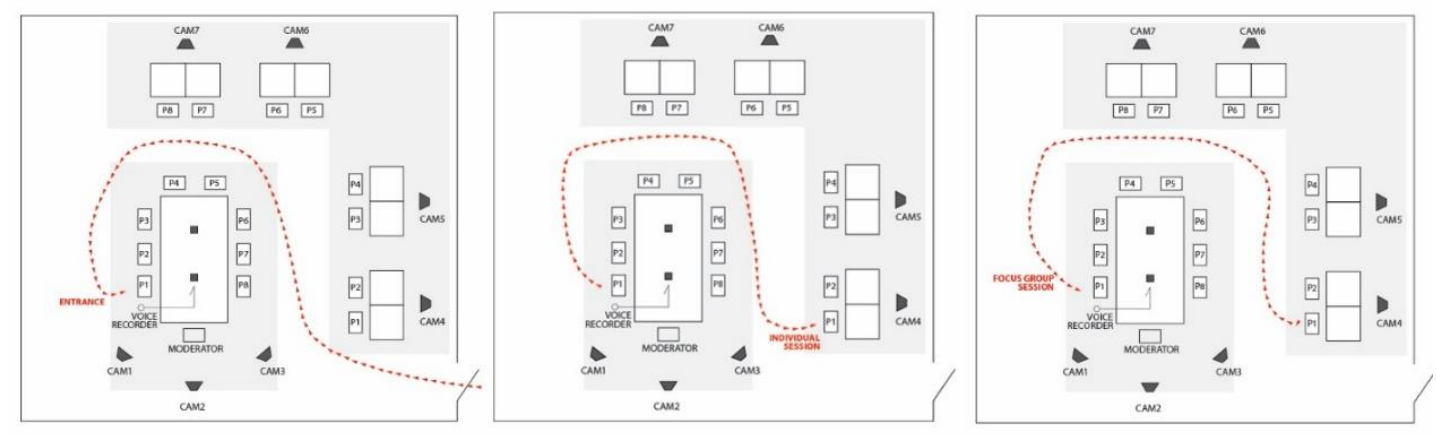

Figure 5: Participant Flow (Participant 1) 


\subsection{Findings and Discussion}

\subsection{Data Sets}

The space design ensures that the data collection process is conducted scientifically and that the study is run systematically. The useful findings of the focused group can be analysed as three data sets. The first set of data from mode 1 is on the captured video of individual sketching exercise which is studied as a time-based analysis (See Figure 6). The second data sets, on the individual argument in their defence to justify their concept and the third data sets of the dynamic discussion as a group when participants work towards consensus building is transcribed and coded for Designerly Intuition themes (See Figure 7)

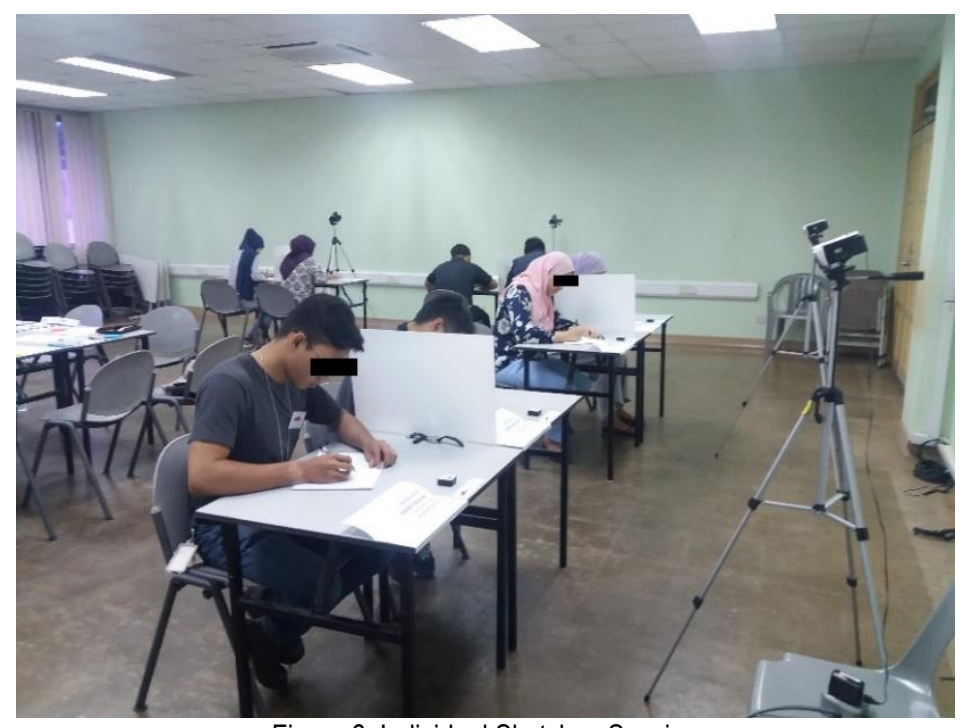

Figure 6: Individual Sketches Session

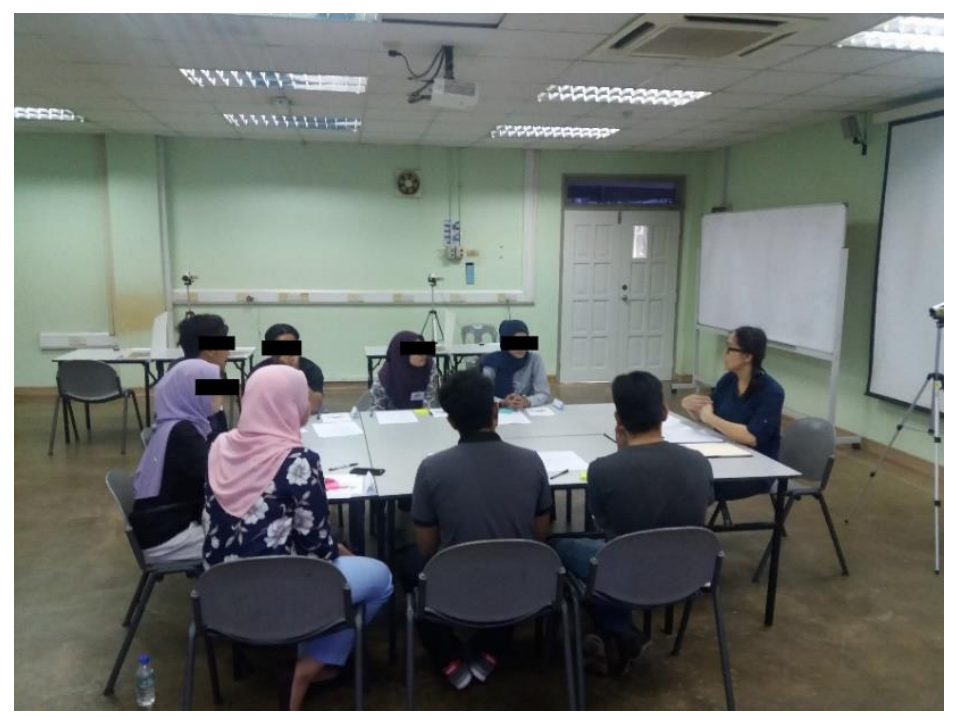

Figure 7: Group discussion Session

\subsection{Principal Researcher and Research Assistant}

Aside from focus group types and structure considerations, the focus group design considerations in an experiment setting in is viewed from a moderator factor. In this case, the human factor relating to the research team member consist of the principal and assistant researcher. The following table (see Table 1) outlines the task division between the principal researcher and research assistant during the various mode and sessions of the research. The outlined task does not include the design of the controlled experiment in the form of Focus Group research as well as the analysis which comes later. Instead, the division of work is centred on the efficiency and strategic division of task between the two member which was designed to avoid overlap and redundancy on the actual day. 
Table 1. Task Division of Research Team during Focus Group as a Controlled Experiment Setting

\begin{tabular}{|c|c|c|c|}
\hline & Task & Principal Researcher & Research Assistant \\
\hline Before & Preparation for Focus Group & $\begin{array}{l}\text { Prepare documents and template, } \\
\text { Sends out invitation and follow up } \\
\text { on participants confirmation }\end{array}$ & Assist P.A in preparation, \\
\hline \multirow[t]{6}{*}{ During } & General Role during sessions & $\begin{array}{l}\text { Moderate sessions, } \\
\text { keep time during sessions, } \\
\text { collect participant consent form, } \\
\text { provide participation token }\end{array}$ & $\begin{array}{l}\text { Welcomes and registers participants, } \\
\text { keeps participants in holding room, } \\
\text { place new document template } \\
\text { systematically, } \\
\text { collect document systematically }\end{array}$ \\
\hline & Mode 1: Warm Up Session & $\begin{array}{l}\text { Welcome and provide opening, } \\
\text { remark and explanation of research }\end{array}$ & $\begin{array}{l}\text { Set sketching materials at Mode } 1 \\
\text { station, } \\
\text { reset timer at Mode } 1 \text { station, } \\
\text { reset Audio Visual Recording Device }\end{array}$ \\
\hline & $\begin{array}{l}\text { Mode 2: Sub-session 1- Individual } \\
\text { Sharing }\end{array}$ & $\begin{array}{l}\text { Moderate session, } \\
\text { keep time }\end{array}$ & $\begin{array}{l}\text { Arrange sketches from previous } \\
\text { session into individual participant files }\end{array}$ \\
\hline & $\begin{array}{l}\text { Mode 2: Sub-session 2- Concept } \\
\text { Defense }\end{array}$ & $\begin{array}{l}\text { Moderate session } \\
\text { keep time }\end{array}$ & $\begin{array}{l}\text { Register and welcome participants for } \\
\text { next session }\end{array}$ \\
\hline & $\begin{array}{l}\text { Mode 2: Sub-session 3- Consensus } \\
\text { Building }\end{array}$ & $\begin{array}{l}\text { Moderate session, } \\
\text { make Closing remark }\end{array}$ & $\begin{array}{l}\text { Contact participants who have not } \\
\text { arrived to confirm attendance }\end{array}$ \\
\hline & $\begin{array}{l}30 \text { minute intervals between } \\
\text { sessions }\end{array}$ & $\begin{array}{l}\text { Reset camera for Mode } 2 \text { station, } \\
\text { reset new template booklet for } \\
\text { Mode } 2 \text { station }\end{array}$ & $\begin{array}{l}\text { Set sketching materials at Mode } 1 \\
\text { station, } \\
\text { reset timer at Mode } 1 \text { station, } \\
\text { reset Audio Visual Recording Device } \\
\text { at Mode } 1 \text { station, } \\
\text { guides participants from holding room }\end{array}$ \\
\hline After & Preparation after Focus Group & $\begin{array}{l}\text { Prepare data for transcription and } \\
\text { analysis }\end{array}$ & Assist P.A in data set preparation \\
\hline
\end{tabular}

The well-coordinated work between the researchers does not only show the effectiveness of having minimal number of researcher for a focus group study, it allows for minimal interaction of participants with outside of the controlled experiments as there are only to individuals at site. It further avoids biasness and unnecessary discussion which may affect the information that is fed to participants outside of the scripted study questions. The minimal number of researchers at site is further enabled with ample audio recording device and data collection template that are well designed to aid easy cataloguing and documentation for later transcription and analysis jobs.

In the future, building on the flexibility of the established Focus Group method, applied into controlled experiments setting, further studies can be done to design better facility set up, specifically for more controlled individual sketching session which can allow individually dedicated camera as well as audio recording devices for every participant. More forms of data sets can be collected at one sitting if participants can verbalise their thoughts whilst sketching. Another strong consideration should be to look into moderator's fatigue during a day-long focus group session. If the research is replicated to have the exact number of participants and sessions, having concurrent focus group space can be beneficial. This limits the number of sessions which a moderator needs to preside over. However, a better moderator's guide design must be made to not only allow for stricter adherence to the flow to allow validity of data, it must be balanced enough to also allow for anticipated alternative scenario for discussions to sidetrack and return to its main discussion. Therefore the moderator factor needs to include preparedness and experienced moderating skills.

\subsection{Conclusion}

Focus Group research using the approach of the social science field have often been applied into Design research studies, albeit with limited understanding and depth except for market orientated approach and only recently ergonomics and new product development. The application into Design Research Methodology is however uncommon especially in its usage to uncover deeper understanding on Designers and Design practice to build new knowledge which serves as a reflection towards the improvements of future Design activities. This study therefore outlines practical application of the incorporation of a controlled experiment setting into the Focus Group Method opening new insights into alternative application into of Design Research, discussed from the focus group types and structure considerations as well as moderator factor.

\section{Acknowledgements}

The authors gratefully acknowledge the help of the Ministry Education of Malaysia in providing the Bestari Perdana Fund, Project 
Number: 600-IRMI/PERDANA 5/3 BESTARI (111/2018) and Research Management Institute of Universiti Teknologi MARA for managing the grant.

\section{References}

Carter, N., Bryant-Lukosius, D., DiCenso, A., Blythe, J., \& Neville, A. J. (2014, September). The use of triangulation in qualitative research. In Oncology nursing forum (Vol. 41, No. 5).

Baskerville, R. L., Kaul, M., \& Storey, V. C. (2015). Genres of Inquiry in Design-Science Research: Justification and Evaluation of Knowledge Production. Mis Quarterly, 39(3), 541-564.

Patton, M. Q. (1999). Enhancing the quality and credibility of qualitative analysis. Health services research, 34(5 Pt 2), 1189.

Blessing, L., Chakrabarti, A., \& Wallace, K. (1995, August). A design research methodology. In Proc. International Conference on Engineering Design 1995 ICED (pp. 50-55).

Dorst, K., \& Dijkhuis, J. (1995). Comparing paradigms for describing design activity. Design studies, 16(2), 261-274.

Cross, N. (2006). The nature and nurture of design ability. Designerly Ways of Knowing, 15-27.

Johansson-Sköldberg, U., Woodilla, J., \& Çetinkaya, M. (2013). Design thinking: past, present and possible futures. Creativity and innovation management, 22(2), 121146.

Luppicini, R. (2003). Reflective action instructional design (RAID): A designer's aid. International Journal of Technology and Design Education, $13(1)$, 75-82.

Lloyd, P., Lawson, B., \& Scott, P. (1995). Can concurrent verbalization reveal design cognition?. Design Studies, 16(2), 237-259.Krueger, R. A., Focus groups: A practical guide for applied research. Sage publications (2014)

Merton, R. E., \& Kendall, P. L. (1953). "The Focused Interview." American Journal of Sociology 51: 541-557, May 1946. Nursing Research, 2(2), 95.

Merton, R. K. (2008). Focused interview. Simon and Schuster.

Langford, J., \& McDonagh, D. (2003). Focus groups: Supporting effective product development. CRC press.

Stewart, D. W., \& Shamdasani, P. N. (2014). Focus groups: Theory and practice (Vol. 20). Sage publications.

Langford, J., \& McDonagh, D. (2002). What can focus groups offer us?. Contemporary Ergonomics, 502-508.

Ness, L. R. (2015). Are we there yet? Data saturation in qualitative research.

Onwuegbuzie, A. J., Dickinson, W. B., Leech, N. L., \& Zoran, A. G. (2009). A qualitative framework for collecting and analyzing data in focus group research. International journal of qualitative methods, 8(3), 1-21.

Grønkjær, M., Curtis, T., de Crespigny, C., \& Delmar, C. (2011). Analysing group interaction in focus group research: Impact on content and the role of the moderator. Qualitative Studies, 2(1), 16-30.

Puchta, C., \& Potter, J. (1999). Asking elaborate questions: Focus groups and the management of spontaneity. Journal of Sociolinguistics, 3(3), 314-335. 